\title{
Development and clinical applications of cancer immunotherapy against PD-1 signaling pathway
}

\author{
Grace Wakabayashi ${ }^{1}$, Yu-Ching Lee ${ }^{2}$, Frank Luh ${ }^{3}$, Chun-Nan Kuo ${ }^{4}$, Wei-Chiao Chang ${ }^{4^{*}}$ and Yun Yen ${ }^{5^{*}}$ (D)
}

\begin{abstract}
Dramatic advances in immune therapy have emerged as a promising strategy in cancer therapeutics. In addition to chemotherapy and radiotherapy, inhibitors targeting immune-checkpoint molecules such as cytotoxic T-lymphocyte antigen-4 (CTLA-4), programmed cell death receptor-1 (PD-1) and its ligand (PD-L1) demonstrate impressive clinical benefits in clinical trials. In this review, we present background information about therapies involving PD-1/PD-L1 blockade and provide an overview of current clinical trials. Furthermore, we present recent advances involving predictive biomarkers associated with positive therapeutic outcomes in cancer immunotherapy.
\end{abstract}

Keywords: Checkpoint inhibitor, Cancer immunotherapy, PD-1 PD-L1 signaling

\section{Background}

In 1992, Honjo et al. from Kyoto University discovered PD-1, a 228 amino acid transmembrane protein expressed in T-cells linked to apoptosis pathway [1]. Subsequent PD-1 mouse studies revealed the immunosuppressive effect of PD-1 knockout. PD-1 deficiency in BALB/c mice cause a variety of autoimmune diseases including dilated cardiomyopathy and gastritis $[2,3]$. PD-1 is expressed in dendritic cells (DCs), B cells and activated T cells [4]. The ligands of PD-1/PD-L1 (B7-H1, CD274) and PD-L2 (B7DC, CD273) were identified in 2000 and 2001, respectively [5-7]. PD-L1 is widely expressed in T cells and endothelial cells and is over expressed in different types of tumor cells. Upon PD-L1 binding to PD-1, T-cell receptor (TCR) signaling is inactivated following SHP2 dephosphorylation. This signaling inactivation suppresses $\mathrm{T}$ cell proliferation, cytokine release, and cytotoxic activity [8]. Experiments in tumor animal models indicate that inhibition of PD-L1 and PD-1 can block tumorigenesis and tumor metastasis via PD-1 mediated T cell activation, a key step for cancer

\footnotetext{
*Correspondence: wcchang@tmu.edu.tw; yyen@tmu.edu.tw

${ }^{4}$ Department of Clinical Pharmacy, School of Pharmacy, Taipei Medical University; Department of Pharmacy, Integrative Therapy Center for

Gastroenterologic Cancers, Wan Fang Hospital; Taipei Medical University, 250

Wu-Hsing Street, Taipei, Taiwan110

${ }^{5}$ PhD Program for Cancer Biology and Drug Discovery, Taipei Medical

University, 250 Wu-Hsing Street, Taipei, Taiwan 110

Full list of author information is available at the end of the article
}

immune therapy [9]. In 2006, Nivolumab, a humanized PD-1 mAb, was developed for phase I clinical trial and was eventually approved by the U.S. Food and Drug Administration (FDA) for patients with malignant melanoma in 2015. Currently, there are six FDA-approved PD1/PD-L1 pathway inhibitors for cancer therapy: nivolumab, pembrolizumab, atezolizumab, durvalumab, cemiplimab and avelumab (Table 1).

\section{Overview of PD-1/PD-L1 and other immune blockades in clinical trials}

Immuno-oncology has proven to be a field with untapped potential in the fight against cancer. Many clinical trials are currently testing different ways to program the body's immune system to target and eliminate tumors. Originally, studies on immune-checkpoint inhibitors (ICIs) focused on certain types of cancers but recent advances in science and research have allowed ICIs to target broader cancer types. Among the most well studied ICIs are monoclonal antibody therapies against PD-1 and PD-L1.

New insight on the interaction between the immune system and tumor growth has identified the PD-1/PD-L1 ligand pathway to be a key player in evading host immune response. By blocking this pathway, checkpoint inhibitors can reprogram the immune system to recognize tumor cells and ultimately destroy them. PD-1/PD-L1 inhibitors have been FDA approved for a wide variety of 
Table 1 US FDA approved PD-1/PD-L1 inhibitors

\begin{tabular}{|c|c|c|c|c|}
\hline Target & Molecule & Approved indications & Company & $\begin{array}{l}\text { Commercial } \\
\text { name }\end{array}$ \\
\hline \multirow[t]{3}{*}{ PD-1 } & $\begin{array}{l}\text { Nivolumab (BMS-936558, } \\
\text { MDX1106, ONO4538) }\end{array}$ & $\begin{array}{l}\text { CRC (MSI high), HNSCC, HCC, Hodgkin lymphoma, melanoma, } \\
\text { NSCLC, RCC, SCLC, UC }\end{array}$ & Bristol-Meyers Squibb/Ono & Opdivo \\
\hline & $\begin{array}{l}\text { Pembrolizumab (MK-3475, } \\
\text { Lambrolizumab) }\end{array}$ & $\begin{array}{l}\text { Cervical cancer, CRC, endometrial cancer, esophageal cancer, } \\
\text { gastric cancer, HNSCC, HCC, Hodgkin lymphoma, melanoma, } \\
\text { Merkel cell carcinoma, MSI high cancer, NSCLC, PMBCL, RCC, } \\
\text { SCLC, UC }\end{array}$ & Merck & Keytruda \\
\hline & Cemiplimab & Cutaneous squamous cell carcinoma & Sanofi & Libtayo \\
\hline \multirow[t]{3}{*}{ PD-L1 } & $\begin{array}{l}\text { Atezolizumab } \\
\text { (MPDL3280A) }\end{array}$ & Breast cancer, NSCLC, SCLC, UC & Roche/Genentech & Tecentriq \\
\hline & Durvalumab (MEDI4736) & NSCLC, UC & $\begin{array}{l}\text { Medlmmune/AstraZeneca/ } \\
\text { Celgene }\end{array}$ & Imfinzi \\
\hline & $\begin{array}{l}\text { Avelumab } \\
\text { (MSB0010718C) }\end{array}$ & Merkel cell carcinoma, RCC, UC & Merck Serono/Pfizer & Bavencio \\
\hline
\end{tabular}

CRC Colorectal cancer, HCC Hepatocellular carcinoma, HNSCC Head and neck squamous cell carcinoma, MSI Microsatellite instability, NSCLC Non-small cell lung cancer, PMBCL Primary mediastinal large B cell lymphoma, RCC Renal cell carcinoma, SCLC Small cell lung cancer, UC Urothelial carcinoma

cancers (Table 1). The majority of published clinical trials have explored use of PD-1/PD-L1 inhibitors in patients diagnosed with melanoma, kidney cancer, head and neck, and non-small cell lung cancer (NSCLC) (Table 2). This review will focus on selected trials involving these cancers.

Historically, PD-1/PD-L1 clinical trials have explored the efficacy of combination chemotherapies with checkpoint inhibitors and use of checkpoint inhibitors as monotherapy. KEYNOTE-006, - 002, CheckMate-066 and -037 studies showed PD-1 inhibitors are beneficial for patients with advanced melanoma [10-13]. The PD1 inhibitors in these trials produced an overall survival (OS) ranging from 16 to 38 months versus the comparative treatment's OS of $11.2-15.9$ months [10, 11, 13]. In CheckMate-025 and -214, urologic cancers, such as metastatic renal cell cancer, reported better clinical outcomes when patients are treated with nivolumab either as monotherapy or combined with ipilimumab (CTLA-4 inhibitor), compared to target therapy alone [14-16]. The overall response rate (ORR) in CheckMate-025 and -214 favored nivolumab over other treatments $(22-42 \%$ vs. 4-29\%) $[14,16]$. Head and neck squamous cell carcinoma (HNSCC) trials such as CheckMate-141 and KEYNOTE 040 proved checkpoint inhibitors were more successful than investigator's choice chemotherapy [17, 18]. CheckMate-141 compared nivolumab against standard therapy and showed an OS of 7.7 vs. 5.1 months [18]. KEYNOTE 040 showed that pembrolizumab, as a monotherapy, was superior to chemotherapy and had an OS of 8.4 vs. 6.9 months [17]. Nivolumab and Pembrolizumab have been approved by the FDA for treatment of HNSCC.

Platinum-based chemotherapy has been the primary treatment for NSCLC without driver mutation for many years. Recently, several trials reported that ICIs have a potential role in the treatment of NSCLC. KEYNOTE 024 demonstrated that pembrolizumab monotherapy was superior to platinum-based chemotherapy in patients with PD-L1 expression level above $50 \%$ as first-line therapy [19]. Progression-free survival (PFS) was 10.3 vs. 6 months and the ORR was $44.8 \%$ vs. $27.8 \%$ [19]. KEYNOTE 189 demonstrated that the combination of pembrolizumab with pemetrexed/platinum-based chemotherapy produced better outcomes in first-line therapy when compared to pemetrexed/ platinum-based chemotherapy alone [20]. The OS of first-line therapy was 11.3 months and the OS for the PD-1 combination was not yet reached [20]. IMpower 150 studied atezolizumab plus chemotherapeutic regimens, containing a platinum and taxane with bevacizumab, versus the same chemotherapeutic regimen without atezolizumab in NSCLC. The PFS was 8.3 months vs. 6.8 months $[21,22]$.

It is important to note that studies that have involved combining two ICIs versus combining an ICI with chemotherapy have led to varying results. For advanced melanoma, CheckMate-067 studied ipilimumab versus nivolumab versus a combination of ipilimumab and nivolumab. Ipilimumab and nivolumab alone reported PFS of 2.9-6.9 months whereas the combination of the two had a PFS of 11.5 months [23]. Grade 3-4 adverse events (AEs) occurring in CheckMate-067 ranged from $16.3-55 \%$ of patients [23]. While there were many benefits found in the combination of nivolumab with ipilimumab, the high percentage of adverse events led to another clinical study, CheckMate-511. In this study nivolumab and ipilimumab were combined and tested in two different ratios, 3:1 and 1:3. The regimen containing the higher ratio of nivolumab to ipilimumab showed lower AEs, longer PFS (9.9 vs. 8.9 months), but fewer ORRs (45.6\% vs. 50.6\%) [24]. 
Table 2 Selected clinical trials of PD-1/PD-L1 immunotherapies according to cancer type

\begin{tabular}{|c|c|c|c|c|c|}
\hline Trial & Subject & Study vs. comparison & Result & Reference & FDA approval outcome \\
\hline \multicolumn{6}{|l|}{ Melanoma } \\
\hline $\begin{array}{l}\text { Keynote } \\
006\end{array}$ & $\begin{array}{l}\text { No prior immunotherapy, } \\
\text { any PD-L1 level }\end{array}$ & P $10 \mathrm{mg} / \mathrm{kg}$ vs. I & $\begin{array}{l}\text { OS: } 32.7 \text { vs. } \\
15.9 \text { months } \\
\text { PFS: } 8.4 \text { vs. } 3.4 \\
\text { months }\end{array}$ & $\begin{array}{l}\text { Schachter } \\
\text { et al. } 2017\end{array}$ & $\begin{array}{l}\text { FDA approved pembrolizumab for first-line } \\
\text { treatment in advanced melanoma }\end{array}$ \\
\hline $\begin{array}{l}\text { Keynote } \\
002\end{array}$ & $\begin{array}{l}\text { With prior ipilimumab, } \\
\text { any PD-L1 level }\end{array}$ & $\begin{array}{l}\mathrm{P} 2 \mathrm{mg} / \mathrm{kg} \text { vs. P } 10 \mathrm{mg} / \\
\mathrm{kg} \text { vs } C\end{array}$ & $\begin{array}{l}\text { PFS: } 34 \% \text { vs. } \\
38 \% \text { vs. } 16 \%\end{array}$ & $\begin{array}{l}\text { Ribas } \\
\text { et al. } 2015\end{array}$ & $\begin{array}{l}\text { FDA approved pembrolizumab for second-line } \\
\text { treatment in advanced melanoma }\end{array}$ \\
\hline $\begin{array}{l}\text { CheckMate } \\
066\end{array}$ & $\begin{array}{l}\text { Previous untreated, } \\
\text { any PD-L1 level }\end{array}$ & $\begin{array}{l}\text { N } 3 \mathrm{mg} / \mathrm{kg} \text { vs. } \\
\text { dacarbazine }\end{array}$ & $\begin{array}{l}\text { OS: } 37.5 \mathrm{vs} . \\
11.2 \text { months } \\
\text { PFS: } 5.1 \text { vs. } 2.2 \\
\text { months }\end{array}$ & $\begin{array}{l}\text { Ascierto } \\
\text { et al. } 2019\end{array}$ & $\begin{array}{l}\text { FDA approved Opdivo for treatment of BRAF } \\
\text { V600 wild-type unresectable or metastatic } \\
\text { melanoma }\end{array}$ \\
\hline $\begin{array}{l}\text { CheckMate } \\
037\end{array}$ & $\begin{array}{l}\text { With prior ipilimumab, } \\
\text { any PD-L1 level }\end{array}$ & N 3 mg/kg vs. C & $\begin{array}{l}\text { OS: } 16 \text { vs. } 14 \\
\text { months } \\
\text { PFS: } 3.1 \text { vs. } 3.7 \\
\text { months } \\
\text { ORR: } 27 \% \text { vs. } \\
\text { 10\% }\end{array}$ & $\begin{array}{l}\text { Larkin } \\
\text { et al. } 2018\end{array}$ & $\begin{array}{l}\text { FDA approved Opdivo for unresectable or } \\
\text { metastatic melanoma following treatment } \\
\text { with ipilimumab or BRAF inhibitor }\end{array}$ \\
\hline $\begin{array}{l}\text { CheckMate } \\
067\end{array}$ & $\begin{array}{l}\text { Previous untreated, } \\
\text { any PD-L1 level }\end{array}$ & $\begin{array}{l}\text { N } 3 \mathrm{mg} / \mathrm{kg}+13 \mathrm{mg} / \mathrm{kg} \\
\text { vs. N } 3 \mathrm{mg} / \mathrm{kg} \text { vs. I } 3 \\
\mathrm{mg} / \mathrm{kg}\end{array}$ & $\begin{array}{l}\text { OS: not } \\
\text { reached vs. } \\
37.6 \text { vs. } 19.9 \\
\text { months } \\
\text { PFS: } 11.5 \text { vs. } \\
6.9 \text { vs. } \\
2.9 \text { months }\end{array}$ & $\begin{array}{l}\text { Larkin } \\
\text { et al. } 2015\end{array}$ & $\begin{array}{l}\text { FDA approved nivolumab in combination } \\
\text { with ipilimumab for treatment of BRAFV } 600 \\
\text { wild-type and BRAF V600 mutation positive } \\
\text { unresectable or metastatic melanoma }\end{array}$ \\
\hline $\begin{array}{l}\text { CheckMate } \\
511\end{array}$ & $\begin{array}{l}\text { Previous untreated, } \\
\text { any PD-L1 level }\end{array}$ & $\begin{array}{l}\text { N } 3 \mathrm{mg} / \mathrm{kg}+\mathrm{I} 1 \mathrm{mg} / \mathrm{kg} \\
\text { vs. N } 1 \mathrm{mg} / \mathrm{kg}+13 \\
\mathrm{mg} / \mathrm{kg}\end{array}$ & $\begin{array}{l}\text { PFS: } 9.9 \text { vs. } 8.9 \\
\text { months } \\
\text { ORR: } 45.6 \% \text { vs. } \\
50.6 \% \\
\text { Grade } 3 \text { to } 5 \\
\text { AEs: } 34 \% \text { vs. } \\
48 \%\end{array}$ & $\begin{array}{l}\text { Lebbe } \\
\text { et al. } 2019\end{array}$ & \\
\hline \multicolumn{6}{|c|}{ Renal Cell Carcinoma } \\
\hline $\begin{array}{l}\text { CheckMate } \\
025\end{array}$ & $\begin{array}{l}\text { With prior treatment, } \\
\text { any PD-L1 level }\end{array}$ & $\begin{array}{l}\text { N } 3 \mathrm{mg} / \mathrm{kg} \text { vs. } \\
\text { everolimus }\end{array}$ & $\begin{array}{l}\text { OS: } 25 \text { vs. } 19.6 \\
\text { months } \\
\text { ORR: } 22 \% \text { vs. } \\
4 \%\end{array}$ & $\begin{array}{l}\text { Escudier } \\
\text { et al. } 2017\end{array}$ & $\begin{array}{l}\text { FDA approved nivolumab for treatment of } \\
\text { advanced renal cell carcinoma with no prior } \\
\text { anti-angiogenic therapy }\end{array}$ \\
\hline $\begin{array}{l}\text { CheckMate } \\
214\end{array}$ & $\begin{array}{l}\text { Previous untreated } \\
\text { intermediate to poor } \\
\text { risk, any PD-L1 level }\end{array}$ & $\begin{array}{l}\text { N } 3 \mathrm{mg} / \mathrm{kg}+11 \mathrm{mg} / \mathrm{kg} \\
\text { vs. sunitinib }\end{array}$ & $\begin{array}{l}\text { OS: not } \\
\text { reached vs. } \\
26.6 \text { months } \\
\text { PFS: } 8.2 \text { vs. } 8.3 \\
\text { months } \\
\text { ORR: } 42 \% \text { vs. } \\
29 \%\end{array}$ & $\begin{array}{l}\text { Motzer et al. } \\
\text { 2019; Escudier } \\
\text { et al. } 2017\end{array}$ & $\begin{array}{l}\text { FDA approved nivolumab and ipilimumab } \\
\text { for treatment of intermediate or poor risk, } \\
\text { previously untreated advanced renal cell } \\
\text { carcinoma }\end{array}$ \\
\hline
\end{tabular}

\section{Non-Small Cell Lung Cancer}

$\begin{array}{ll}\text { Keynote } & \text { Previous untreated, } \\ 024 & \text { with TPS over 50\% }\end{array}$

Keynote

189

Previous untreated, any PD-L1 level

Keynote With prior treatment, 010 any PD-L1 level
P 200 mg vs. C

OS: $80.2 \%$ vs.

$72.4 \%$

PFS: 10.3 vs. 6 months

ORR: $44.8 \%$ vs. $27.8 \%$

P $200 \mathrm{mg}+$ C vs. C

OS: not reached vs.

11.3 months

PFS: 8.8 vs. 4.9 months

P $2 \mathrm{mg} / \mathrm{kg}$ vs. P $10 \mathrm{mg} /$ Total $\mathrm{kg}$ vs. docetaxel

population

OS: 10.4 vs.

12.7 vs.

8.5 months

PFS: 3.9 vs. 4.0
Reck et al. 2016

Gandhi et al. 2018

Herbst et al. 2016
FDA approved pembrolizumab for treatment of metastatic NSCLC whose tumors have high PD-LA expression with no EGFR or ALK genomic tumor aberrations

FDA approved pembrolizumab in combination with pemetrexed and platinum chemotherapy for first line treatment of metastatic non squamous NSCLC with no EGFR or ALK genomic tumor aberrations

FDA approved pembrolizumab as second-line treatment for PD-L1 Positive non-small cell lung cancer 
Table 2 Selected clinical trials of PD-1/PD-L1 immunotherapies according to cancer type (Continued)

\begin{tabular}{|c|c|c|c|c|c|}
\hline Trial & Subject & Study vs. comparison & Result & Reference & FDA approval outcome \\
\hline & & & $\begin{array}{l}\text { vs. } 4.0 \text { months } \\
\text { TPS } \geq 50 \% \\
\text { OS: } 14.9 \text { vs. } \\
17.3 \text { vs. } \\
8.2 \text { months } \\
\text { PFS: } 5.0 \text { vs. } 5.2 \\
\text { vs. } 4.1 \text { months }\end{array}$ & & \\
\hline $\begin{array}{l}\text { IMpower } \\
150\end{array}$ & $\begin{array}{l}\text { Nonsquamous, } \\
\text { previous untreated, } \\
\text { any PD-L1 level }\end{array}$ & $\begin{array}{l}\text { A } 1200 \mathrm{mg}+\mathrm{C}+ \\
\text { bevacizumab } 15 \mathrm{mg} / \mathrm{kg} \\
\text { vs. } \\
\text { C + bevacizumab }\end{array}$ & $\begin{array}{l}\text { PFS: } 8.3 \text { vs. } 6.8 \\
\text { months }\end{array}$ & $\begin{array}{l}\text { Socinski et al., } \\
2018\end{array}$ & $\begin{array}{l}\text { FDA approved atezolizumab in combination } \\
\text { with bevacizumab, paclitaxel, and carboplatin } \\
\text { for first line treatment of metastatic } \\
\text { non-squamous non-small cell lung cancer } \\
\text { with no EGFR or ALK genomic } \\
\text { tumor aberrations }\end{array}$ \\
\hline \multicolumn{6}{|c|}{ Head and Neck Cancer } \\
\hline $\begin{array}{l}\text { Keynote } \\
040\end{array}$ & $\begin{array}{l}\text { With prior treatment, } \\
\text { any PD-L1 level }\end{array}$ & P 200 mg vs. C & $\begin{array}{l}\text { OS: } 8.4 \text { vs. } 6.9 \\
\text { months }\end{array}$ & $\begin{array}{l}\text { Cohen et al. } \\
2018\end{array}$ & $\begin{array}{l}\text { FDA approved pembrolizumab for treatment } \\
\text { of recurrent or metastatic squamous cell } \\
\text { carcinoma of head and neck with disease } \\
\text { progression on or after platinum-based } \\
\text { therapy }\end{array}$ \\
\hline $\begin{array}{l}\text { CheckMate } \\
141\end{array}$ & $\begin{array}{l}\text { With prior treatment, } \\
\text { any PD-L1 level }\end{array}$ & N 3 mg/kg vs. C & $\begin{array}{l}\text { OS7.5 vs. } 5.1 \\
\text { months }\end{array}$ & $\begin{array}{l}\text { Kiyota et al. } \\
2017\end{array}$ & $\begin{array}{l}\text { FDA approved nivolumab for treatment of } \\
\text { recurrent or metastatic squamous cell } \\
\text { carcinoma of head and neck with disease } \\
\text { progression on or after platinum-based } \\
\text { therapy }\end{array}$ \\
\hline
\end{tabular}

A Atezolizumab, AES Adverse events, C Chemotherapy, D Durvalumab, I lpilimumab, N, Nivolumab, ORR Objective response rate, OS Overall survival, $P$ Pembrolizumab, PFS Progression-free survival, TPS Tumor proportion score

Immunotherapy combined with chemotherapy or targeted therapy may offer improved clincial outcomes. In addition to the previously mentioned trials KEYNOTE189 and IMpower150, atezolizumab combined with nabpaclitaxel also provided longer PFS in patients with triple negative breast cancer compared to nab-paclitaxel alone [25]. Furthermore, in patients with renal cell carcinoma, KEYNOTE-426 trial demonstrated that pembrolizumab plus axitinib leaded longer PFS compared to standard sunitinib treatment [26]. From these studies, the combination of immunotherapy with chemotherapy or target therapy not only benefit in longer PFS but also higher objective response rate.

\section{Immunotherapy associated with biomarkers in tumor microenvironment}

Numerous studies have focused on identifying biomarkers that can predict treatment efficacy (Table 3). For example, PD-L1 has proven to be a good predictive biomarker when using pembrolizumab in NSCLC patients. In KEYNOTE 010 trial, patients with PD-L1 levels over $50 \%$ had higher ORR, PFS and OS compared to total population [27]. Treatment benefit was further demonstrated in KEYNOTE 024 phase 3 trial, which supported pembrolizumab as first-line therapy for metastatic NSCLC [19]. In KEYNOTE 042 study, the benefit was still observed in patient with tumor proportion score (TPS) greater than 50\% compared to those with TPS score 1-49\% [28]. However, the correlation between PD-L1 expression level and treatment effect was not observed in other cancer types or in studies with other immunotherapy agents [29-31]. The indications with consideration about PD-L1 expression were listed in Table 4. More recently, Lee et al., reported a novel method to remove the glycosylation of PD-L1. In such cases, de-glycosylation might enhance PD-L1 detection and improve the accuracy of PD-L1 quantification and prediction of PD-1/PD-L1 immune checkpoint blockade therapies [32].

Mismatch-repair deficiency has also proven to be another practical predictive biomarker for immunotherapy. Le et al. demonstrated that ORR of pembrolizumab in patients with metastatic colon cancer was higher in patients with mismatch-repair deficiency compared to those with mismatch-repair proficiency. In patients with mismatch-repair deficiency, the ORR was $40 \%$ and disease control rate was $90 \%$. In contrast, in patients with mismatch repair proficiency, no response could be seen [33]. Overman et al. also reported similar treatment benefit of nivolumab in patients with metastatic colon cancer and mismatch-repair deficiency. In that study, the ORR was $31 \%$ and the disease control rate was $69 \%$ [34]. Le et al. further demonstrated a treatment benefit of pembrolizumab in solid tumors with mismatch-repair deficiency, including colorectal cancer, endometrial cancer, gastroesophageal cancer and eight other types of cancer. The ORR was 53\% and disease control rate was 77\% [35]. Taken together, these results offer a strong 
Table 3 Predictive biomarkers for treatment efficacy of PD-1/PD-L1 targeting agents

\begin{tabular}{|c|c|c|c|c|}
\hline Drug & Sample & Marker & Result & Reference \\
\hline Pembrolizumab & NSCLC & $P D-L 1^{*}$ & $\uparrow:$ longer OS \& PFS & $\begin{array}{l}\text { Herbst et al., 2016; Reck et al., 2016; } \\
\text { Mok et al., } 2019\end{array}$ \\
\hline Pembrolizumab & $\begin{array}{l}\text { Metastatic colon } \\
\text { cancer }\end{array}$ & $M M R^{*}$ & Deficiency: ORR $=40 \%, D C R=90 \%$ & Le et al., 2016 \\
\hline Pembrolizumab & 11 cancer types & $M M R^{*}$ & Deficiency: ORR $=53 \%$, DCR $=77 \%$ & Le et al., 2017 \\
\hline Nivolumab & NSCLC & $\mathrm{TMB}$ & $\uparrow:$ longer PFS & Carbone et al., 2017 \\
\hline Nivolumab+lpilimumab & $\mathrm{NSCLC}$ & $\mathrm{TMB}$ & $\uparrow:$ longer OS \& PFS & Hellmann et al., 2018 \\
\hline Nivolumab & melanoma & $\mathrm{ALC}$ & $\geq 1000 \mathrm{u} / \mathrm{L}: \uparrow$ prognosis & Nakamura et al. 2016 \\
\hline Nivolumab & melanoma & ANC & $<4000 \mathrm{u} / \mathrm{L}: \uparrow$ prognosis & Nakamura et al. 2016 \\
\hline Ipilimumab & melanoma & $\mathrm{NLR}+\mathrm{LDH}$ & $\mathrm{NLR}>2.2 \& \uparrow L D H: \downarrow R R$ & Bagley et al., 2017 \\
\hline PD-1 targeted therapy & NSCLC & Ki67 & $\uparrow:$ positive outcomes & Kamphorst et al., 2017 \\
\hline Pembrolizumab & melanoma & TCR repertoire & $\downarrow$ diversity: positive clonal responses & Tumeh, et al., 2014 \\
\hline Nivolumab & $\begin{array}{l}\text { Metastatic } \\
\text { melanoma }\end{array}$ & $\begin{array}{l}P D-L 1+G Z M A+ \\
\text { HLA-A }\end{array}$ & $\uparrow:$ better clinical outcomes & Hiroyuki et al., 2016 \\
\hline Nivolumab & $\begin{array}{l}\text { Metastatic } \\
\text { melanoma }\end{array}$ & TCR repertoire & $\downarrow$ diversity: $\uparrow$ responses & $\begin{array}{l}\text { Hiroyuki et al., 2016; } \\
\text { Sabrina et al., } 2018\end{array}$ \\
\hline PD-1 targeted therapy & melanoma & $\begin{array}{l}\text { Ruminococcaceae } \\
\text { family }\end{array}$ & $\begin{array}{l}\uparrow \text { alpha diversity \& relative abundance: } \uparrow \\
\text { responses }\end{array}$ & Gopalakrishnan et al., 2018 \\
\hline PD-1 targeted therapy & $\begin{array}{l}\text { Lung \& kidney } \\
\text { cancers }\end{array}$ & $\begin{array}{l}\text { Akkermansia } \\
\text { muciniphila }\end{array}$ & $\uparrow$ relative abundance: $\uparrow$ responses & Routy et al., 2018 \\
\hline
\end{tabular}

* PD-L1 and MMR are clinically applicable biomarkers

NSCLC Non-small-cell lung carcinoma, OS Overall survival, PFS Progression free survival, ORR Overall response rate, DCR Disease control rate, TMB Tumor mutation burden, $A L C$ Absolute lymphocyte count, NLR Neutrophil-to-lymphocyte ratio, $L D H$ Lactate dehydrogenase, $R R$ Response rate, $T C R$ T-cell receptor

case for mismatch-repair deficiency as a biomarker in patient selection for immune checkpoint blockade across cancer types. In 2017, U.S. Food and Drug Administration (FDA) approved pembrolizumab for unresectable or metastatic mismatch-repair deficient solid tumors that progressed following prior treatment.

Tumor mutation burden (TMB) has also been widely discussed as a potential predictive biomarker for immunotherapy. In CheckMate 026 study, despite unsuccessful treatment benefit for NSCLC patients with nivolumab or chemotherapy, PFS was significantly longer in high TMB subgroup when separating nivolumab group based on the level of TMB, [36]. In CheckMate
227 trial, nivolumab plus ipilimumab also provided longer PFS and ORR in patients with high TMB compared to those receiving chemotherapy, irrespective of PD-L1 expression level or tumor histology type [37]. Cristescu et al. evaluated hundreds of samples with different cancer types from four trials involving pembrolizumab and found that TMB was correlated with the PFS among groups of pan-tumor, head and neck cancer and melanoma [38]. TMB studies involving liquid biopsies have also demonstrated encouraging results; however, samples from these biopsies are still challenging and inconsistent. Georgiadis et al. used liquid biopsy to test the mismatch-repair deficiency and TMB. Results

Table 4 Indications with consideration about biomarkers in advanced cancers

\begin{tabular}{llll}
\hline & Pembrolizumab & Nivolumab & Atezolizumab \\
\hline Breast cancer, triple negative, first-line & - & - & IC $\geq 1 \%$ \\
Cervical cancer, second-line & CPS $\geq 1$ & - & - \\
Colorectal cancer, second-line & MSI-high & MSI-high & - \\
Esophageal cancer, second-line & CPS $\geq 10$ & - & - \\
Gastric cancer, second-line & CPS $\geq 1$ & - & - \\
Head and neck cancer, first-line & CPS $\geq 1$ & - & - \\
Non-small cell lung cancer, first-line & CPS $\geq 1$ & - & - \\
Urothelial carcinoma, first-line & CPS $\geq 10$ & - & IC $\geq 5 \%$ \\
Solid tumor, second-line & MSI-high & - \\
\hline
\end{tabular}


demonstrated the feasibility of noninvasive screening for mismatch-repair deficiency and TMB in the prediction of PD-1 blockade efficacy [39]. In 2017, Foundation One testing was approved by US FDA for TMB detection.

In spite of its application to aid in patient selection, the assessment of TMB is still plagued by a number of uncertainties. First, TMB has been measured by various methods. Hence, changes in the cut-off definitions as well as alterations in the number of gene panel may affect results. Second, some TMB evidence is obtained from chromosomal structural analyses or mutational status from selected genes [40]. As the reports with LRP1B, KRAS, MSH2 and MSH6 demonstrate, these approaches can only be useful in specific cancer types [41-43]. Third, the difficulties in obtaining sufficient tissue samples as well as good quality of DNA available from biopsy limits the implementation of TMB test. In this respect, standardized evaluation of TMB and better noninvasive sampling methods are needed.

Although PD-L1 expression, mismatch-repair, and TMB are considered potential biomarkers to predict efficacy of various immune therapies, growing evidence suggests other factors like neutrophil to lymphocyte ratio (NLR), lactate dehydrogenase (LDH), and Ki-67 might be valuable markers for prognosis in cancer patients receiving immune therapy. For example, absolute lymphocyte count greater than $1000 \mathrm{u} / \mathrm{L}$ and absolute neutrophil count less than $4000 \mathrm{u} / \mathrm{L}$ were reported to be associated with the treatment outcomes in patients with advanced melanoma treated with nivolumab [44]. In addition, high NLR has been shown to be associated with poor response [44]. Hazama et al. ported that NLR $<3.0$ correlated with longer survival in cancer patients with peptide vaccine treatment [45]. Recent resources also revealed a critical role for NLR and $\mathrm{LDH}$ in the regulation of melanoma treated with ipilimumab [46]. High levels of NLR (greater than 2.2) combined with high serum LDH level are associated with non-response. Importantly, in the lung cancer patients treated with nivolumab, NLR $\geq 5$ correlated with poor therapeutic outcome, suggesting NLR is a potential predictive markers in immune therapy [47]. Moreover, NLR was reported as a marker for the outcomes of chemotherapy in advanced cancer [48]. Despite intense investigation and some encouraging results on NLR, the mechanism underlying this correlation remains unclear.

There are still many potential predictive biomarkers for cancer immune therapy. For example, Ki67 is a marker of cell proliferation and $\mathrm{T}$-cell reinvigoration. Kamphorst et al. reported that increase in Ki-67+ PD-1+ CD8 T cells serve as a marker that correlates with positive clinical outcomes for NSCLC patients receiving PD-1-targeted therapies [49]. A particularly important example of how T-cell invigoration can predict response to anti-PD-1 therapy comes from a study in human melanoma. Huang et al. indicated that high Ki67 to tumor burden ratio correlates with a better clinical outcome [50]. In addition, there is considerable evidence for a role of $\mathrm{T}$ cell receptor repertoire in cancer immune therapy. In melanoma, Tumeh at al. indicated that low diversity of $\mathrm{T}$ cell repertoire in tumor infiltrating lymphocytes associated with positive clinical responses of pembrolizumab [51]. Hiroyuki et al. provided evidence that high expression of PD-1 ligands, granzyme A, and HLA-A correlated with a better clinical outcome with nivolumab. A decreased diversity of $\mathrm{T}$ cell repertoire was observed in the tumor tissue of nivolumab responders [52]. Consistent with this were the findings that using peripheral blood $\mathrm{T}$ cell receptor repertoire analysis, Sabrina et al. further indicated that low diversity of immune repertoire can be a predictive marker of anti-PD1 therapy [53]. Recently, most interest has focused on gut microbiome, which is thought to influence the clinical responses of anti-PD-1 immune therapy [54, 55]. Immunoscore (see 'Current Challenges and future perspectives for PD-1/PD-L1 therapy') is another area of interest for useful prognostic information about predicting response to treatment. However, the challenge remains in identifying individual immunoprofiles of each patient as well as the consequent choice of optimal therapy to predict drug effect. To date, no single biomarker is considered the gold standard for predictive or clinical use in cancer immunotherapy.

\section{Adverse events in cancer patients treated with PD-1/PD- L1 blockade}

PD-1/PD-L1 inhibitors are becoming prominent cancer therapies due to their efficacy and their relatively mild adverse events (AEs) compared to chemotherapeutic agents. However, the AEs caused by PD-1/PD-L1 inhibitors are considerable and require further research. Some of the most well documented AEs associated with PD-1/ PD-L1 inhibitors fall into several categories: dermatologic, gastrointestinal, hepatic, pulmonary, cardiovascular, and endocrine. Other common AEs include, but are not limited to, fatigue, uveitis and myositis (Fig. 1).

Of the dermatologic AEs associated with PD-1/PD-L1 inhibitors, rash and pruritus are the most predominant [56]. A 2019 meta-analysis by Yang et al. found that patients receiving PD-1/PD-L1 inhibitors have an increased risk of developing pruritus and rash when compared to patients receiving chemotherapy [57]. This same study showed that patients receiving ipilimumab as a monotherapy had an increased risk of developing pruritus compared to patients treated with PD-1/PD-L1 inhibitors. Both of these AEs deeply impact the quality of life for patients. Preventative treatment along with accurate diagnosis of dermatologic AEs can reduce treatment discontinuation and improve overall outcomes. 


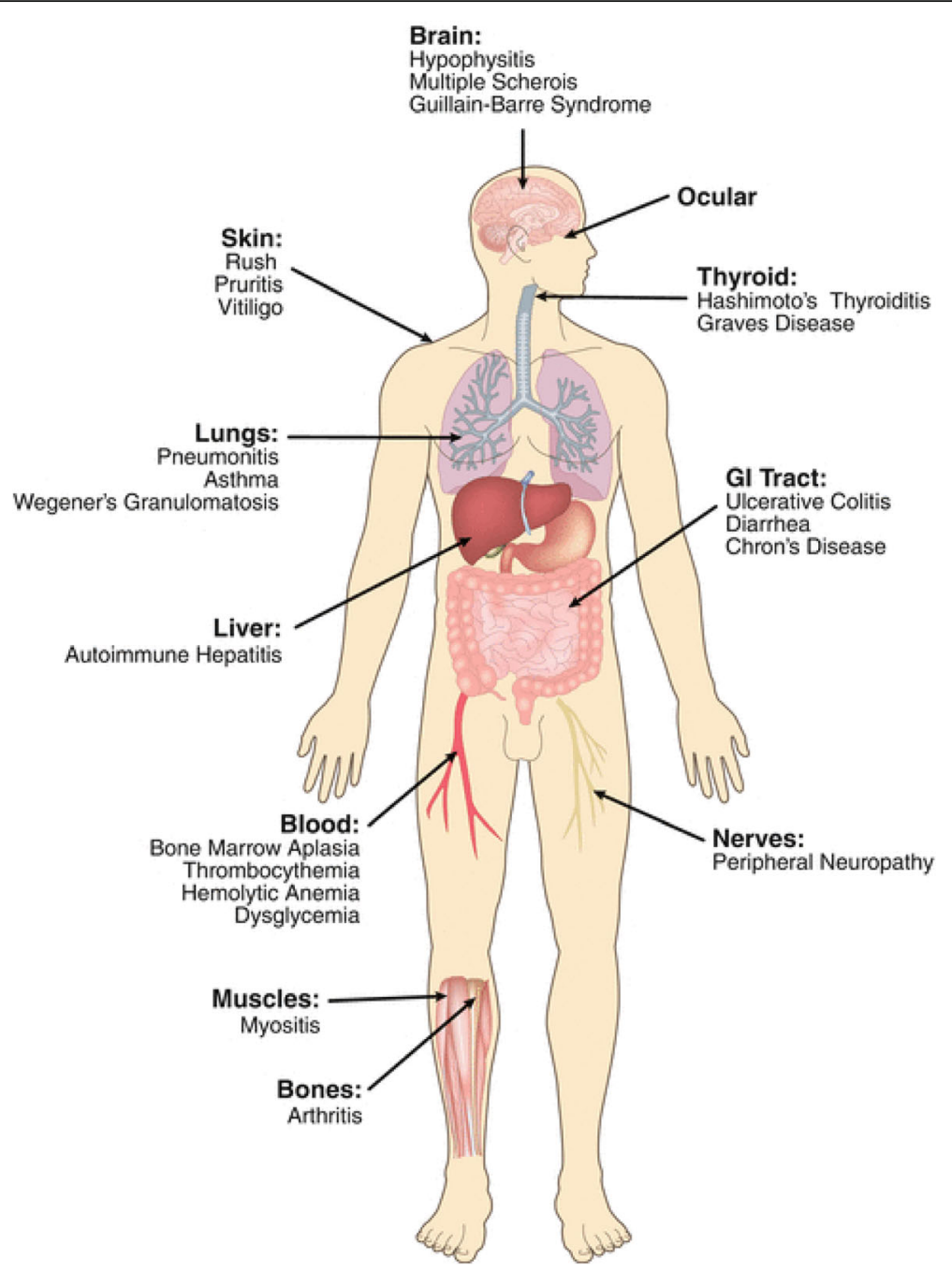

Fig. 1 Complete Spectrum of adverse events associated with cancer immunotherapy. Depicted are common immune-related adverse events in patients treated with immune checkpoint blockade (modified from Festino L. and Ascierto P.A. (2018) "Side Effects of Cancer Immunotherapy with Checkpoint Inhibitors." In: Zitvogel L., Kroemer G. (eds) Oncoimmunology. Springer, Cham)

Gastrointestinal AEs of PD-1/PD-L1 inhibitors include colitis and diarrhea. Symptoms of colitis may include abdominal pain, fever, and abnormal stools. High grade colitis has potentially fatal consequences such as GI tract perforation, ischemia, necrosis, or toxic megacolon [58]. CheckMate 064 reported colitis was the most common treatment-related G3-4 AE and the most common reason for discontinuing treatment [59]. Diarrhea may be a symptom of colitis or a separate AE induced by a checkpoint inhibitor. Regardless, diarrhea must be treated to avoid a hydroelectrolytic imbalance. Symptoms of diarrhea include an increase of number of stools per day that surpass the patient's baseline [58]. Diarrhea of a G4 $\mathrm{AE}$ could include life threatening symptoms such as hemodynamic collapse [58].

Hepatic AEs of PD-1/PD-L1 inhibitors affect a low percentage of patients [60]. However, liver toxicity can be fatal. Patient's liver function should be monitored closely. Elevated aspartate aminotransferase (AST) and alanine aminotransferase (ALT) are indicators of hepatic AEs. Before treatment with PD-1/PD-L1 inhibitors, a patient's history of autoimmune disease and/or chronic viral infections should be taken into account. While it is uncommon, hepatitis $\mathrm{B} / \mathrm{C}(\mathrm{HBV} / \mathrm{HCV})$ and/or human immunodeficiency virus (HIV) can be exacerbated by immunotherapy [60, 61]. It is recommended that patients with underlying hepatitis or autoimmune disease be followed by a specialist in their field while receiving PD-1/PD-L1 inhibitors [60, 61].

Pneumonitis can be a fatal AE associated with PD-1/ PD-L1 inhibitors [62]. A meta-analysis completed in 2019 found that treatment with PD-1/PD-L1 inhibitors - nivolumab, pembrolizumab, and atezolizumab - increase the risk of pneumonitis $[62,63]$. Pembrolizumab was the only 
PD-1/PD-L1 inhibitor found to have a greater risk of pneumonitis compared to chemotherapeutic agents [62] Ipilimumab did not demonstrate an increased risk of pneumonitis [62]. The combination of ipilimumab with nivolumab was reported to have more pulmonary AEs than ipilimumab or nivolumab as monotherapies [64].

Myocarditis, an inflammatory $\mathrm{AE}$, is the most common cardiovascular toxicity associated with ICIs [65]. Patients who receive a combination of nivolumab and ipilimumab compared with those who receive nivolumab alone have a higher risk for myocarditis [66, 67]. Presentation of myocarditis could involve elevated serum cardiac biomarkers such as cardiac troponin and creatine kinasemuscle/brain [68]. Myocardial inflammation can also cause shortness of breath and in severe cases lead to cardiogenic shock. The diagnosis of myocarditis requires the use of an MRI scan, PET scan, CT scan, and/or an echocardiogram $[65,66]$. In specific cases, an endomyocardial biopsy may be necessary. It is crucial that myocarditis be diagnosed and treated in its early stages as more advanced myocarditis is highly fatal. Patients with ICI induced myocarditis are also seen to have myositis or myasthenia gravis $[65,69]$. If a patient presents with myocarditis, it is important to check for other concurrent AEs.

Endocrine AEs include hypothyroidism, hyperthyroidism, and primary adrenal insufficiency. These have been linked to various PD-1/PD-L1 inhibitors. Thyroid disorders are diagnosed by measuring thyroid-stimulating hormone (TSH), thyroxine(T4), triiodothyronine (T3) levels, and thyroid antibodies. Elevated TSH and suppressed T4 indicate hypothyroidism and suppressed TSH and elevated T4 and/or T3 levels indicate hyperthyroidism [70]. Clinical symptoms of thyroid disorders such as fatigue, sensitivity to temperature, constipation, dry skin and fluctuating weight are difficult to differentiate from other diseases [71]. Therefore, measurements of TSH, T4, and T3 levels are crucial for proper diagnosing. A recent Meta-Analysis reported that PD-1/PD-L1 inhibitors have a higher risk of primary thyroid dysfunction when compared to anti-CTLA-4 [72]. Primary adrenal insufficiency is extremely rare but worth noting due to its association with need for life-long treatment and high fatality rates [73]. Low cortisol and high adrenocorticotropic hormone $(\mathrm{ACTH})$ are indicators of primary adrenal insufficiency [70]. Clinical presentations may include asthenia, fever, abdominal pain, vomiting, diarrhea, and weight loss [73].

Myositis and myasthenia gravis are both neuromuscular disorders which can occur with PD-1/PD-L1 inhibitor therapy. Pembrolizumab specifically has been documented to elevate risk of myositis and myasthenia gravis in patients [74]. Symptoms of myositis may include elevated creatine kinase or limb weakness [75].
Interstitial pneumonitis and cardiac toxicity have been found to occur concurrent with myositis [75]. Myasthenia gravis can present with orthopnea, dyspnea, or weakness in facial muscles [75]. While neuromuscular disorders are relatively rare among AEs in patients undergoing immunotherapy, they still require great attention and research so that prompt recognition and treatment can improve outcomes.

Ophthalmologic AEs of PD-1/PD-L1 inhibitors are rare but can deeply impact a patient's quality of life. Uveitis is generally the most common form of ophthalmologic AEs with symptoms of eye redness, pain, blurred vision, and photophobia [76]. Both ipilimumab and nivolumab as monotherapies have been reported to increase ophthalmologic AEs in patients [76, 77]. Uveitis as an AE is usually minor but, in some cases, can cause blindness and the discontinuation of immunotherapy may be required [78].

\section{Management of immune-related adverse events in cancer patients treated with PD-1/PD-L1 blockade}

Detailed tracking of AEs secondary to different ICIs will lead to improved patient treatments and outcomes. Some AEs associated with immunotherapy are fatal and other AEs are severe and can deeply diminish patient quality of life. As the study of efficacy regarding PD-1/PD-L1 inhibitors continues, the treatment of immune related AEs (irAEs) must also advance. Detailed algorithms regarding the management of immunotherapy-related toxicities can be found in the $\mathrm{Na}$ tional Comprehensive Cancer Network Clinical Practice Guidelines (NCCN Guidelines) (Fig. 2, [79]).

Rash and pruritus are among the most common AEs and usually require a set of general recommendations to keep skin AEs under control. These recommendations include wearing loose clothing, avoiding hot shower/baths, using unscented soaps, applying sunscreen when outside and moisturizing the skin regularly [80]. An itching management should be taught to patients so that a secondary infection does not arise from cuts on the skin. For the treatment of severe rash and pruritus, corticosteroids, antihistamines, antibiotics, or retinoids should be prescribed [81]. Patients with G2-3 dermatologic AEs may require the discontinuation of immunotherapy due to the discomfort and impairment of patient's quality of life.

Colitis and diarrhea range from relatively mild to fatal AEs. Symptoms of colitis include abdominal pain, fever, and abnormal stools $[58,59]$. Higher grade colitis can be potentially fatal [58]. These severe side effects may require an immunosuppressive drug such as infliximab and discontinuation of treatment [58]. Infliximab is an immunosuppressant and works by neutralizing tumor necrosis factor alpha (TNF $\alpha$ ) [82]. Infliximab has been used to treat inflammatory colitis such as Crohn's disease and ulcerative colitis. Lower grade colitis can be treated with 


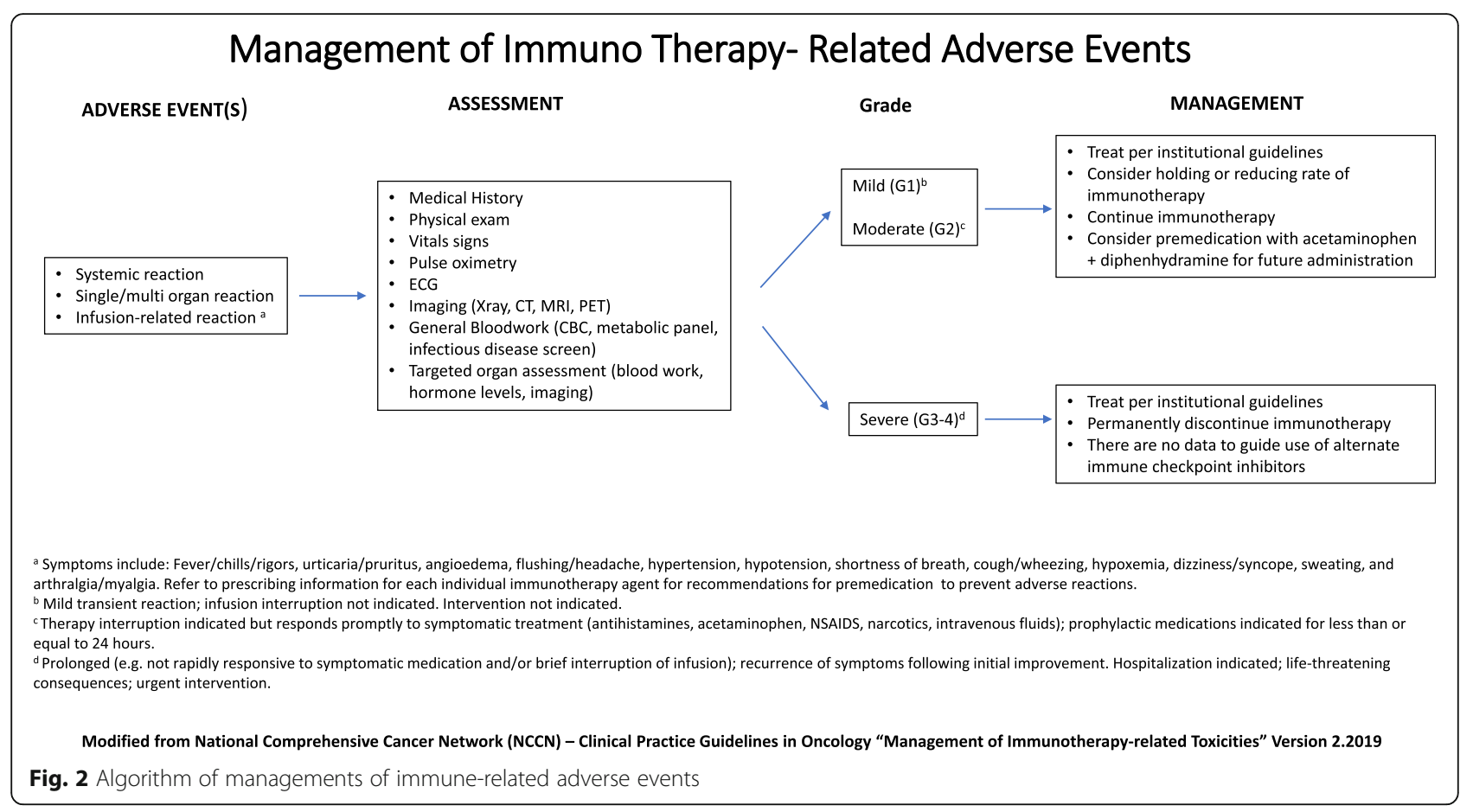

corticosteroids, but if the patient does not respond to corticosteroids, infliximab should be given. Treatment for mild to moderate diarrhea includes hydration and a low fiber diet. If diarrhea is severe enough to include life threatening symptoms such as hemodynamic collapse, immediate intravenous fluid resuscitation and discontinuation of treatment is required [58].

Immune-mediated hepatitis is another severe side effect of PD-1/PD-L1 inhibitors. Routine monitoring of liver enzymes allows for prompt diagnosis and treatment of liver toxicities. For G2-4 hepatitis, steroid therapy should be used [83]. In this case, if there is no response to steroid therapy, treatment with infliximab is not recommended as it can further increase hepatotoxicity [83]. A non-respondent steroid patient should undergo a liver biopsy to confirm and clarify hepatitis associated with PD-1/PD-L1 inhibitors. Treatment for a non-respondent steroid patient includes a direct-acting antiviral or ursodiol therapy [83].

Pneumonitis secondary to PD-1/PD-L1 inhibitors can be associated with death. Treatment of pneumonitis most commonly includes corticosteroids, but in some cases involves cyclophosphamide and infliximab [84, 85]. The cessation of treatment is common in G3-4 pneumonitis. Early recognition of pneumonitis is essential for the treatment and recovery of patients.

Myocarditis is not a common $\mathrm{AE}$ associated with $\mathrm{PD}-1 /$ PD-L1 inhibitors but has a high mortality rate. The diagnoses and treatment of myocarditis is extremely important when administering ICIs. Treatment of myocarditis includes use of steroids with other classic heart failure management
[67]. Anti-thymocyte globulin, an immunosuppressive treatment, has been reported as an effective drug against myocarditis. Infliximab has been used as a treatment after highdose steroids fail but has been associated with heart failure in patients with rheumatoid arthritis [86].

Endocrine dysfunctions are common AEs. Hypothyroidism and hyperthyroidism rarely have severe symptoms and can be treated with hormone manipulation [70, 72]. It is advised that thyroid dysfunction, grade 2 or lower, do not require cessation of immunotherapy [70]. Grades 3 and 4 hypothyroidism can be treated with levothyroxine and hyperthyroidism. Grade 3 and 4 hyperthyroidism can be treated with steroids and other forms of therapy to prevent a thyrotoxic storm [70]. Primary adrenal insufficiency should be treated with gluco- and mineralocorticosteriods [70, 72]. Depending on the severity of primary adrenal insufficiency, hormone replacement therapy may be life-long [73].

Myositis and myasthenia gravis are both neuromuscular disorders that can be AEs of PD-1/PD-L1 inhibitors. Myositis treatment includes a combination of steroids, plasmapheresis and intravenous immunoglobulins [87]. Similarly, myasthenia gravis should be treated with corticosteroids and possibly immunosuppressive drugs. In some cases, cholinesterase inhibitors have been given to patients for temporary symptom relief [88].

Uveitis should be taken seriously as it can lead to blindness. Uveitis is treated with systemic or topical steroids $[77,78]$. In high grade cases, the complete discontinuation of immunotherapy is required. It is advised to consult both a dermato-oncologist and ophthalmologist $[77,78]$. 


\section{Current challenges and future perspectives for PD-1/PD-L1 therapy}

Immune checkpoint therapies have been clinically observed to induce sustained response in cancer patients; however, most treatment failures are due to primary resistance. In some cases, cancer progresses after the primary response; but this is probably the result of systematic acquired resistance [89, 90]. Such resistance originates from cancer immunoediting comprising of three phaseselimination, equilibrium, and escape-to constrain the immune system and evade detection by the immune system, thereby facilitating tumor growth [91]. An extremely complex tumor microenvironment can explain variability in immune checkpoint therapies. Even in a single patient, metastatic lesions in different areas of the body elicit heterogeneous responses to therapy. Both intrinsic and extrinsic factors of the tumor microenvironment contribute to the development of such resistance. Intrinsic resistance originates from a loss of neoantigens, changes in the antigen presentation mechanism due to dysregulation of major histocompatibility complex (MHC), defective immunosuppressive genes, and immune cell infiltration or function pathway changes [92-96]. Extrinsic factors include the expression of Treg cells, myeloid-derived suppressor cells (MDSCs), M2 macrophages, and other inhibitory immune checkpoint molecules, all of which inhibit antitumor immune responses $[89,97,98]$. Understanding these resistance factors facilitates the development of new strategies for overcoming resistance and provides theoretical support for personalized immunotherapy.

Individual biological differences can explain varied clinical responses to immune checkpoint therapies. Therefore, the ability to predict immune response before administering treatment will be particularly crucial. Researchers have yet to succeed in using specific biomarkers to predict therapeutic effects and treatment-induced toxic responses. Numerous emerging immune checkpoint molecules have been deemed promising targets, but no specific concomitant biomarker has been identified. Therefore, development of novel predictive biomarkers is a pressing matter. The vital criteria to be considered when developing predictive biomarkers are identifying correlations between the biomarker and clinical outcome, low complexity, high reproducibility, low cost, and ease of standardization [99]. Only recent clinical research has looked at specific biomarkers to serve as a basis for application of immune checkpoint inhibitors. Selective CD8+ T-cell infiltration, the distribution of $\mathrm{T}$-cells at tumor invasive margins, and PD-L1 expression were found to be associated with clinical response to anti-PD-1/PD-L1 therapy [51, 100-102]. Studies demonstrate that specific genes involved in chromatin remodeling (i.e., PBRM1, ARID2, and BRD7) can be used as markers for predicting responses. The epithelial mesenchymal transition is highly associated with tumor microenvironment changes including elevated inflammatory signals and enhanced expression of multiple immune checkpoints in lung cancer [103]. Another promising biomarker is a change or defect in the DNA damage response (DDR) pathway, and such DDR variants have also been discovered in numerous tumors [104]. The number and density of tumor-infiltrating lymphocytes can be standardized to form a simple classification system called immunoscore, which might serve as a useful indicator of effectiveness of immune checkpoint therapies with high prognostic value. The immunoscore ranges from I0 (the lowest) to I4 (the highest) and distinguishes tumors (primary or metastatic) according to their degree of immune infiltration, thereby classifying them into two categories-hot and cold. Hot tumors contain high levels of infiltrating T-cells and usually respond favorably to immune checkpoint inhibitors $[105$, 106]. Cold tumors lack infiltrating T-cells and have low PD-L1 expression, high cell proliferation, and a low mutation burden; moreover, lack of tumor antigenicity and immunogenicity result in no activation of $\mathrm{T}$-cells and thus an unfavorable response to immune checkpoint therapy.

Absence of T-cells at the tumor site also suggests there is no antitumor $\mathrm{T}$-cell response. The CD8+ T-cells at tumor sites play a crucial role in the therapeutic effect of PD-1 inhibitors. Therefore, PD-1 inhibitors are ineffective in the microenvironment of cold tumors. Because hot tumors have highly favorable and multiple inhibitory immune checkpoint molecule expression, the therapeutic strategy for these tumors should involve using multiple brakes on the host immune system to revitalize previously activated T-cells to boost the immune response. Regarding the therapeutic strategy for cold tumors, the microenvironment composition of the tumor should be stimulated through heat before immune checkpoint inhibitors are applied. Literature reports that type I interferon (IFN) and signaling pathway in autophagy are associated with immunogenic cell death (ICD) response. The released danger-associated molecular patterns (DAMP) activated by the immune system's microenvironment in response to cellular stress and death can promote antigenicity expression [107]. These regulations alter the tumor microenvironment and make it more receptive to immune checkpoint inhibitor therapy. Finally, although application of immune checkpoint inhibitors in cancer treatment show great potential and enormous opportunities, the high price of immunotherapies results in a high cost per life, thus limiting the use of these therapies for suitable patients.

\section{Conclusion}

Recent work reveals a central role of PD-1 signaling pathway in cancer immunotherapy. Although data from clinical trials provides exciting results for PD1/PD-L1 inhibitors in advanced cancer therapy, challenges in clinical use still remain. First, when using PD-1/PD-L1 
inhibitor alone without biomarkers selection, the ORR is around $10-25 \%$ and time to response is within 2-4 months $[17,18,30,31,108]$. For patients with advanced cancer and visceral crisis, these agents do not ensure ability to control tumor in a short time. Second, the costs of PD-1/PD-L1 inhibitors are still expensive. The monthly cost of immunotherapy is around 2-5 times higher compared to the cost of standard targeted therapy [109]. The extremely high cost limits affordability for most patients. Finally, although several factors have been proposed to predict the anti-PD-1 immune therapy, no predictive markers are available for clinical use. To ensure the technical reliability as well as clinical utility of immune therapy for cancer patients, improvements in standardization of predictive biomarker assessments and large-scale randomized trials are warranted.

\begin{abstract}
Abbreviations
AE: Adverse event; ALT: Alanine aminotransferase; AST: Aspartate aminotransferase; CTLA-4: Cytotoxic T-lymphocyte antigen-4; DAMP: Dangerassociated molecular patterns; DC: Dendritic cells; DDR: DNA damage response; FDA: Food and Drug Administration; HBV/HCV: Hepatitis B/C; HIV: Human immunodeficiency virus; HNSCC: Head and neck squamous cell carcinoma; ICD: Immunogenic cell death; ICI: Immune-checkpoint inhibitors; IFN: interferon; irAEs: Immune related adverse events; LDH: Lactate dehydrogenase; MDSCs: Myeloid-derived suppressor cells; MHC: Major histocompatibility complex; NLR: Neutrophil to lymphocyte ratio; NSCLC: Non-small cell lung cancer; ORR: Overall response rate; OS: Overall survival; PD-1: Programmed cell death receptor-1; PD-L1: Programmed deathligand-1; PFS: Progression-free survival; TCR: T cell receptor; TMB: Tumor mutation burden; TPS: Tumor proportion score
\end{abstract}

\section{Acknowledgements}

Not applicable.

\section{Authors' contributions}

All authors (GW, YCL, FL, CNK, WCC, and YY) contributed equally in the writing and preparation of this article. All authors read and approve the final manuscript. G.W. collected all information and composed sections related to adverse effects of immunotherapy. W.C.C. and C.N.K. performed literature review of all basic research involving immunotherapy and wrote introduction and biomarkers section. Y.C.L. wrote future developments in immuno-oncology. F.L. reviewed and edited entire manuscript. Y.Y. designed entire manuscript and arranged all information related to clinical trials.

\section{Funding}

This work was financially supported by the TMU Research Center of Cancer Translational Medicine from the Featured Areas Research Center Program within the framework of the Higher Education Sprout Project by the Ministry of Education (MOE) in Taiwan.

\section{Availability of data and materials}

Data and materials related to this work are available upon request.

\section{Ethics approval and consent to participate}

Not applicable.

\section{Consent for publication}

Not applicable.

\section{Competing interests}

The authors declare no competing interests.

\section{Author details}

${ }^{1}$ Taipei Medical University, 250 Wu-Hsing Street, Taipei, Taiwan $110 .{ }^{2}$ Center for Cancer Transnational Research, Taipei Medical University, 250 Wu-Hsing
Street, Taipei, Taiwan 110. ${ }^{3}$ Sino-American Cancer Foundation, 668 Arrow Grand Circle, Suite 101, Covina, California 91722, USA. ${ }^{4}$ Department of Clinical Pharmacy, School of Pharmacy, Taipei Medical University; Department of Pharmacy, Integrative Therapy Center for Gastroenterologic Cancers, Wan Fang Hospital; Taipei Medical University, 250 Wu-Hsing Street, Taipei, Taiwan 110. ${ }^{5} \mathrm{PhD}$ Program for Cancer Biology and Drug Discovery, Taipei Medical University, 250 Wu-Hsing Street, Taipei, Taiwan110.

Received: 2 October 2019 Accepted: 13 November 2019

Published online: 05 December 2019

\section{References}

1. Ishida Y, et al. Induced expression of PD-1, a novel member of the immunoglobulin gene superfamily, upon programmed cell death. EMBO J. 1992:11(11):3887-95.

2. Nishimura $\mathrm{H}$, et al. Development of lupus-like autoimmune diseases by disruption of the PD-1 gene encoding an ITIM motif-carrying immunoreceptor. Immunity. 1999;11(2):141-51.

3. Nishimura $\mathrm{H}$, et al. Autoimmune dilated cardiomyopathy in PD-1 receptordeficient mice. Science. 2001;291(5502):319-22.

4. Barber $\mathrm{DL}$, et al. Restoring function in exhausted CD8 T cells during chronic viral infection. Nature. 2006;439(7077):682-7.

5. Latchman Y, et al. PD-L2 is a second ligand for PD-1 and inhibits T cell activation. Nat Immunol. 2001;2(3):261-8.

6. Freeman GJ, et al. Engagement of the PD-1 immunoinhibitory receptor by a novel B7 family member leads to negative regulation of lymphocyte activation. J Exp Med. 2000;192(7):1027-34.

7. Dong $\mathrm{H}$, et al. B7-H1, a third member of the B7 family, co-stimulates T-cell proliferation and interleukin-10 secretion. Nat Med. 1999;5(12):1365-9.

8. Okazaki T, et al. A rheostat for immune responses: the unique properties of PD-1 and their advantages for clinical application. Nat Immunol. 2013;14(12): 1212-8.

9. Iwai Y, et al. Involvement of PD-L1 on tumor cells in the escape from host immune system and tumor immunotherapy by PD-L1 blockade. Proc Natl Acad Sci U S A. 2002;99(19):12293-7.

10. Ascierto PA, et al. Survival outcomes in patients with previously untreated BRAF wild-type advanced melanoma treated with Nivolumab therapy: three-year follow-up of a randomized phase 3 trial. JAMA Oncol. 2019;5(2):187-94

11. Larkin J, et al. Overall survival in patients with advanced melanoma who received Nivolumab versus Investigator's choice chemotherapy in CheckMate 037: a randomized, controlled, open-label phase III trial. J Clin Oncol. 2018:36(4):383-90.

12. Ribas A, et al. Pembrolizumab versus investigator-choice chemotherapy for ipilimumab-refractory melanoma (KEYNOTE-002): a randomised, controlled, phase 2 trial. Lancet Oncol. 2015;16(8):908-18.

13. Schachter J, et al. Pembrolizumab versus ipilimumab for advanced melanoma: final overall survival results of a multicentre, randomised, openlabel phase 3 study (KEYNOTE-006). Lancet. 2017;390(10105):1853-62.

14. Motzer RJ, et al. Nivolumab plus ipilimumab versus sunitinib in first-line treatment for advanced renal cell carcinoma: extended follow-up of efficacy and safety results from a randomised, controlled, phase 3 trial. Lancet Oncol. 2019.

15. Motzer RJ, et al. Nivolumab plus Ipilimumab versus Sunitinib in advanced renal-cell carcinoma. N Engl J Med. 2018;378(14):1277-90.

16. Escudier B, et al. CheckMate 025 randomized phase 3 study: outcomes by key baseline factors and prior therapy for Nivolumab versus Everolimus in advanced renal cell carcinoma. Eur Urol. 2017;72(6):962-71.

17. Cohen EEW, et al. Pembrolizumab versus methotrexate, docetaxel, or cetuximab for recurrent or metastatic head-and-neck squamous cell carcinoma (KEYNOTE-040): a randomised, open-label, phase 3 study. Lancet. 2019;393(10167):156-67.

18. Kiyota $\mathrm{N}$, et al. A randomized, open-label, phase III clinical trial of nivolumab vs. therapy of investigator's choice in recurrent squamous cell carcinoma of the head and neck: a subanalysis of Asian patients versus the global population in checkmate 141. Oral Oncol. 2017;73:138-46.

19. Reck M, et al. Pembrolizumab versus chemotherapy for PD-L1-positive nonsmall-cell lung Cancer. N Engl J Med. 2016;375(19):1823-33.

20. Gandhi L, et al. Pembrolizumab plus chemotherapy in metastatic non-smallcell lung Cancer. N Engl J Med. 2018;378(22):2078-92. 
21. Socinski MA, et al. Atezolizumab for first-line treatment of metastatic nonsquamous NSCLC. N Engl J Med. 2018;378(24):2288-301.

22. West $\mathrm{H}$, et al. Atezolizumab in combination with carboplatin plus nabpaclitaxel chemotherapy compared with chemotherapy alone as first-line treatment for metastatic non-squamous non-small-cell lung cancer (IMpower130): a multicentre, randomised, open-label, phase 3 trial. Lancet Oncol. 2019;20(7):924-37.

23. Larkin J, et al. Combined Nivolumab and Ipilimumab or Monotherapy in untreated melanoma. N Engl J Med. 2015;373(1):23-34.

24. Lebbe $C$, et al. Evaluation of two dosing regimens for Nivolumab in combination with Ipilimumab in patients with advanced melanoma: results from the phase IIIb/IV CheckMate 511 trial. J Clin Oncol. 2019; 37(11):867-75.

25. Schmid $\mathrm{P}$, et al. Atezolizumab and nab-paclitaxel in advanced triplenegative breast Cancer. N Engl J Med. 2018;379(22):2108-21.

26. Rini Bl, et al. Pembrolizumab plus Axitinib versus Sunitinib for advanced renal-cell carcinoma. N Engl J Med. 2019;380(12):1116-27.

27. Herbst RS, et al. Pembrolizumab versus docetaxel for previously treated, PDL1-positive, advanced non-small-cell lung cancer (KEYNOTE-010): a randomised controlled trial. Lancet. 2016;387(10027):1540-50.

28. Mok TSK, et al. Pembrolizumab versus chemotherapy for previously untreated, PD-L1-expressing, locally advanced or metastatic non-small-cell lung cancer (KEYNOTE-042): a randomised, open-label, controlled, phase 3 trial. Lancet. 2019;393(10183):1819-30.

29. Rittmeyer A, et al. Atezolizumab versus docetaxel in patients with previously treated non-small-cell lung cancer (OAK): a phase 3, open-label, multicentre randomised controlled trial. Lancet. 2017;389(10066):255-65.

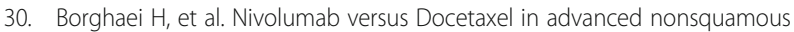
non-small-cell lung Cancer. N Engl J Med. 2015;373(17):1627-39.

31. Bellmunt J, et al. Pembrolizumab as second-line therapy for advanced Urothelial carcinoma. N Engl J Med. 2017;376(11):1015-26.

32. Lee HH, et al. Removal of N-linked glycosylation enhances PD-L1 detection and predicts anti-PD-1/PD-L1 therapeutic efficacy. Cancer Cell. 2019;36(2): 168-78 e4.

33. Le DT, et al. PD-1 blockade in tumors with mismatch-repair deficiency. N Engl J Med. 2015;372(26):2509-20.

34. Overman MJ, et al. Nivolumab in patients with metastatic DNA mismatch repair-deficient or microsatellite instability-high colorectal cancer (CheckMate 142): an open-label, multicentre, phase 2 study. Lancet Oncol. 2017;18(9):1182-91.

35. Le DT, et al. Mismatch repair deficiency predicts response of solid tumors to PD-1 blockade. Science. 2017;357(6349):409-13.

36. Carbone DP, et al. First-line Nivolumab in stage IV or recurrent non-smallcell lung Cancer. N Engl J Med. 2017;376(25):2415-26.

37. Hellmann MD, et al. Nivolumab plus Ipilimumab in lung Cancer with a high tumor mutational burden. N Engl J Med. 2018;378(22):2093-104.

38. Cristescu, R., et al., Pan-tumor genomic biomarkers for PD-1 checkpoint blockade-based immunotherapy. Science, 2018;362(6411).

39. Georgiadis A, et al. Noninvasive detection of microsatellite instability and high tumor mutation burden in Cancer patients treated with PD-1 blockade. Clin Cancer Res. 2019.

40. Devarakonda S, et al. Tumor mutation burden as a biomarker in resected non-small-cell lung Cancer. J Clin Oncol. 2018;36(30):2995-3006.

41. Vanderwalde A, et al. Microsatellite instability status determined by nextgeneration sequencing and compared with PD-L1 and tumor mutational burden in 11,348 patients. Cancer Med. 2018;7(3):746-56.

42. Fabrizio DA, et al. Beyond microsatellite testing: assessment of tumor mutational burden identifies subsets of colorectal cancer who may respond to immune checkpoint inhibition. J Gastrointest Oncol. 2018;9(4):610-7.

43. Johnson DB, et al. Targeted next generation sequencing identifies markers of response to PD-1 blockade. Cancer Immunol Res. 2016;4(11):959-67.

44. Nakamura $Y$, et al. Nivolumab for advanced melanoma: pretreatment prognostic factors and early outcome markers during therapy. Oncotarget. 2016;7(47):77404-15

45. Hazama S, et al. A phase lotal study of five peptides combination with oxaliplatin-based chemotherapy as a first-line therapy for advanced colorectal cancer (FXV study). J Transl Med. 2014;12:108.

46. Fujisawa $Y$, et al. Baseline neutrophil to lymphocyte ratio combined with serum lactate dehydrogenase level associated with outcome of nivolumab immunotherapy in a Japanese advanced melanoma population. $\mathrm{Br} J$ Dermatol. 2018;179(1):213-5.
47. Bagley SJ, et al. Pretreatment neutrophil-to-lymphocyte ratio as a marker of outcomes in nivolumab-treated patients with advanced non-small-cell lung cancer. Lung Cancer. 2017;106:1-7.

48. Lee BM, et al. The neutrophil-lymphocyte ratio and platelet-lymphocyte ratio are prognostic factors in patients with locally advanced pancreatic Cancer treated with Chemoradiotherapy. Gut Liver.

2018;12(3):342-52.

49. Kamphorst AO, et al. Proliferation of PD-1+CD8 T cells in peripheral blood after PD-1-targeted therapy in lung cancer patients. Proc Natl Acad Sci U S A. 2017;114(19):4993-8.

50. Huang $A C$, et al. T-cell invigoration to tumour burden ratio associated with anti-PD-1 response. Nature. 2017:545(7652):60-5.

51. Tumeh PC, et al. PD-1 blockade induces responses by inhibiting adaptive immune resistance. Nature. 2014;515(7528):568-71.

52. Inoue $\mathrm{H}$, et al. Intratumoral expression levels of PD-L1, GZMA, and HLAA along with oligoclonal $T$ cell expansion associate with response to nivolumab in metastatic melanoma. Oncoimmunology. 2016;5(9): e1204507.

53. Hogan SA, et al. Peripheral blood TCR repertoire profiling may facilitate patient stratification for immunotherapy against melanoma. Cancer Immunol Res. 2019;7(1):77-85.

54. Routy B, et al. Gut microbiome influences efficacy of PD-1-based immunotherapy against epithelial tumors. Science. 2018;359(6371):91-7.

55. Gopalakrishnan V, et al. Gut microbiome modulates response to anti-PD-1 immunotherapy in melanoma patients. Science. 2018;359(6371):97-103.

56. Ensslin CJ, et al. Pruritus in patients treated with targeted cancer therapies: systematic review and meta-analysis. J Am Acad Dermatol. 2013;69(5):708-20.

57. Yang W, Li S, Yang Q. Risk of dermatologic and mucosal adverse events associated with PD-1/PD-L1 inhibitors in cancer patients: a meta-analysis of randomized controlled trials. Medicine (Baltimore). 2019;98(20):e15731.

58. Som A, et al. Immune checkpoint inhibitor-induced colitis: a comprehensive review. World J Clin Cases. 2019;7(4):405-18.

59. Weber JS, et al. Sequential administration of nivolumab and ipilimumab with a planned switch in patients with advanced melanoma (CheckMate 064): an open-label, randomised, phase 2 trial. Lancet Oncol. 2016;17(7):943-55.

60. Zhang $X$, et al. Incidence and risk of hepatic toxicities with PD-1 inhibitors in cancer patients: a meta-analysis. Drug Des Devel Ther. 2016;10:3153-61.

61. Spano JP, et al. Immunotherapy for cancer in people living with HIV: safety with an efficacy signal from the series in real life experience. AIDS. 2019; 33(11):F13-9.

62. Su Q, et al. Risk of pneumonitis and pneumonia associated with immune checkpoint inhibitors for solid tumors: a systematic review and metaanalysis. Front Immunol. 2019;10:108.

63. Naidoo J, et al. Pneumonitis in patients treated with anti-programmed Death-1/programmed death ligand 1 therapy. J Clin Oncol. 2017;35(7): 709-17.

64. Wolchok JD, et al. Overall survival with combined Nivolumab and Ipilimumab in advanced melanoma. N Engl J Med. 2017;377(14):1345-56.

65. Hu JR, et al. Cardiovascular toxicities associated with immune checkpoint inhibitors. Cardiovasc Res. 2019;115(5):854-68.

66. Salem JE, et al. Cardiovascular toxicities associated with immune checkpoint inhibitors: an observational, retrospective, pharmacovigilance study. Lancet Oncol. 2018;19(12):1579-89.

67. Martin Huertas $\mathrm{R}$, et al. Cardiac toxicity of immune-checkpoint inhibitors: a clinical case of nivolumab-induced myocarditis and review of the evidence and new challenges. Cancer Manag Res. 2019;11:4541-8.

68. Mahmood SS, et al. Myocarditis in patients treated with immune checkpoint inhibitors. J Am Coll Cardiol. 2018;71(16):1755-64.

69. Moslehi JJ, et al. Increased reporting of fatal immune checkpoint inhibitorassociated myocarditis. Lancet. 2018;391(10124):933.

70. Del Rivero J, et al. Endocrine-related adverse events related to immune checkpoint inhibitors: proposed algorithms for management. Oncologist. 2019.

71. Ferrari, S.M., et al., Autoimmune Endocrine Dysfunctions Associated with Cancer Immunotherapies. Int J Mol Sci, 2019;20(10).

72. de Filette J, et al. A systematic review and meta-analysis of endocrinerelated adverse events associated with immune checkpoint inhibitors. Horm Metab Res. 2019;51(3):145-56.

73. Haissaguerre $M$, et al. Expert opinions on adrenal complications in immunotherapy. Ann Endocrinol (Paris). 2018;79(5):539-44. 
74. Kamo H, et al. Pembrolizumab-related systemic myositis involving ocular and hindneck muscles resembling myasthenic gravis: a case report. BMC Neurol. 2019;19(1):184.

75. Spain $L$, et al. How we treat neurological toxicity from immune checkpoint inhibitors. ESMO Open. 2019;4(Suppl 4):e000540.

76. Wilson MA, et al. Acute visual loss after ipilimumab treatment for metastatic melanoma. J Immunother Cancer. 2016;4:66.

77. Obata S, et al. Vogt-Koyanagi-Harada disease-like uveitis during Nivolumab (anti-PD-1 antibody) treatment for metastatic cutaneous malignant melanoma. Case Rep Ophthalmol. 2019;10(1):67-74.

78. Chang $C J$, et al. Bilateral anterior uveitis after immunotherapy for malignant melanoma. Taiwan J Ophthalmol. 2018;8(3):173-5.

79. Thompson JA, et al. Management of Immunotherapy-Related Toxicities, version 1.2019. J Natl Compr Cancer Netw. 2019;17(3):255-89.

80. Gravalos C, et al. Clinical management of cutaneous adverse events in patients on targeted anticancer therapies and immunotherapies: a national consensus statement by the Spanish academy of dermatology and venereology and the Spanish Society of Medical Oncology. Clin Trans Oncol. 2019;21(5):556-71.

81. Manchen E, Robert C, Porta C. Management of tyrosine kinase inhibitorinduced hand-foot skin reaction: viewpoints from the medical oncologist, dermatologist, and oncology nurse. J Support Oncol. 2011;9(1):13-23.

82. Infliximab, in LiverTox: Clinical and Research Information on Drug-Induced Liver Injury. 2012: Bethesda (MD).

83. Hsu C, Marshall $J L$, He AR. Workup and Management of Immune-Mediated Hepatobiliary Pancreatic Toxicities that Develop during Immune Checkpoint Inhibitor Treatment. Oncologist. 2019.

84. Topalian SL, et al. Survival, durable tumor remission, and long-term safety in patients with advanced melanoma receiving nivolumab. J Clin Oncol. 2014; 32(10):1020-30

85. Akella P, et al. Anti PD-1 immunotherapy related interstitial lung disease presenting as respiratory failure - a review with case series. Respir Med Case Rep. 2019;26:17-22.

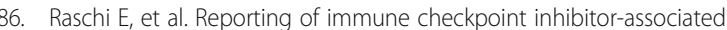
myocarditis. Lancet. 2018;392(10145):383.

87. Iqbal SM, Burns L, Zhi C. Granulomatous myositis associated with myasthenia gravis: a rare case. Cureus. 2019;11(7):e5090.

88. Guptill JT, Soni M, Meriggioli MN. Current treatment, emerging translational therapies, and new therapeutic targets for autoimmune myasthenia gravis. Neurotherapeutics. 2016;13(1):118-31.

89. Sharma $\mathrm{P}$, et al. Primary, adaptive, and acquired resistance to Cancer immunotherapy. Cell. 2017;168(4):707-23.

90. Kelderman S, Schumacher TN, Haanen JB. Acquired and intrinsic resistance in cancer immunotherapy. Mol Oncol. 2014;8(6):1132-9.

91. O'Donnell JS, Teng MWL, Smyth MJ. Cancer immunoediting and resistance to T cell-based immunotherapy. Nat Rev Clin Oncol. 2019; 16(3):151-67.

92. Takeda $\mathrm{K}$, et al. IFN-gamma is required for cytotoxic T cell-dependent cancer genome immunoediting. Nat Commun. 2017;8:14607.

93. Shin DS, et al. Primary resistance to PD-1 blockade mediated by JAK1/2 mutations. Cancer Discov. 2017;7(2):188-201.

94. Ozcan $\mathrm{M}$, et al. Complex pattern of immune evasion in MSI colorectal cancer. Oncoimmunology. 2018;7(7):e1445453.

95. Fares $\mathrm{CM}$, et al. Mechanisms of resistance to immune checkpoint blockade: why does checkpoint inhibitor immunotherapy not work for all patients? Am Soc Clin Oncol Educ Book. 2019;39:147-64.

96. Anagnostou $V$, et al. Evolution of Neoantigen landscape during immune checkpoint blockade in non-small cell lung Cancer. Cancer Discov. 2017:7(3):264-76.

97. Shayan G, et al. Adaptive resistance to anti-PD1 therapy by Tim-3 upregulation is mediated by the PI3K-Akt pathway in head and neck cancer Oncoimmunology. 2017;6(1):e1261779.

98. Jenkins RW, Barbie DA, Flaherty KT. Mechanisms of resistance to immune checkpoint inhibitors. Br J Cancer. 2018;118(1):9-16.

99. van der Burg SH, et al. Harmonization of immune biomarker assays for clinical studies. Sci Transl Med. 2011;3(108):108ps44.

100. Taube JM, et al. Colocalization of inflammatory response with B7-h1 expression in human melanocytic lesions supports an adaptive resistance mechanism of immune escape. Sci Transl Med. 2012:4(127):127ra37.
101. Nakashima C, et al. The effect of oral royal jelly administration on skin barrier function: a double-blind randomized placebo-controlled trial. Eur J Dermatol. 2018;28(4):563-4.

102. Llosa NJ, et al. The vigorous immune microenvironment of microsatellite instable colon cancer is balanced by multiple counter-inhibitory checkpoints. Cancer Discov. 2015;5(1):43-51.

103. Lou Y, et al. Epithelial-Mesenchymal transition is associated with a distinct tumor microenvironment including elevation of inflammatory signals and multiple immune checkpoints in lung adenocarcinoma. Clin Cancer Res. 2016;22(14):3630-42.

104. Bever KM, Le DT. DNA repair defects and implications for immunotherapy. J Clin Invest. 2018;128(10):4236-42.

105. Galon J, et al. Immunoscore and Immunoprofiling in cancer: an update from the melanoma and immunotherapy bridge 2015. J Transl Med. 2016; 14:273.

106. Galon J, Bruni D. Approaches to treat immune hot, altered and cold tumours with combination immunotherapies. Nat Rev Drug Discov. 2019; 18(3):197-218.

107. Galluzzi L, et al. Immunogenic cell death in cancer and infectious disease. Nat Rev Immunol. 2017:17(2):97-111.

108. Motzer RJ, et al. Nivolumab versus Everolimus in advanced renal-cell carcinoma. N Engl J Med. 2015:373(19):1803-13.

109. Kuo CN, et al. Cancers in Taiwan: practical insight from epidemiology, treatments, biomarkers, and cost. J Formos Med Assoc. 2019

\section{Publisher's Note}

Springer Nature remains neutral with regard to jurisdictional claims in published maps and institutional affiliations.
Ready to submit your research? Choose BMC and benefit from:

- fast, convenient online submission

- thorough peer review by experienced researchers in your field

- rapid publication on acceptance

- support for research data, including large and complex data types

- gold Open Access which fosters wider collaboration and increased citations

- maximum visibility for your research: over $100 \mathrm{M}$ website views per year

At BMC, research is always in progress.

Learn more biomedcentral.com/submissions 